\title{
Optical Coherence Tomography Biomarkers: Vitreous Status Influence in Outcomes for Diabetic Macular Edema Therapy with 0.19-mg Fluocinolone Acetonide Implant
}

\author{
Bernardete Pessoa ${ }^{a, b}$ André Ferreira ${ }^{a, c}$ João Leite ${ }^{a}$ João Figueira ${ }^{d, e}$ \\ Angelina Meireles ${ }^{a, b}$ João Melo Beirão ${ }^{a, b}$ \\ aDepartment of Ophthalmology, Centro Hospitalar Universitário do Porto, Porto, Portugal; bepartment of \\ Ophthalmology, Instituto de Ciências Biomédicas Abel Salazar, University of Porto, Porto, Portugal; 'Unit of \\ Anatomy, Department of Biomedicine, Faculty of Medicine of University of Porto, Porto, Portugal; ' ${ }^{\mathrm{d} F a c u l t y}$ of \\ Medicine of the University of Coimbra, Coimbra, Portugal; ${ }^{\mathrm{e} A s s o c i a t i o n ~ f o r ~ I n n o v a t i o n ~ a n d ~ B i o m e d i c a l ~ R e s e a r c h ~ o n ~}$ \\ Light and Image, Coimbra, Portugal
}

\section{Keywords}

Diabetic macular edema - Diabetic retinopathy - Vitrectomy · Fluocinolone acetonide · Biomarkers

\begin{abstract}
Background: The 0.19-mg fluocinolone acetonide (FAc) implant (ILUVIEN ; Alimera Sciences Ltd., Hampshire, UK) was approved for the treatment of vision impairment associated with chronic and refractory diabetic macular edema (DME). Objectives: To quantitatively assess functional and structural features in nonvitrectomized and vitrectomized DME patients after being treated with an FAc implant. Methods: Retrospective review of patients with DME receiving a single intravitreal injection of the FAc implant. The study was designed to analyze the presence of quantitative structural OCT biomarkers at baseline and 12 months after FAc therapy according to vitreous status. Results: $A$ total of 41 eyes from 30 patients were included in this study. At 12 months after injection, vitrectomized patients had a lower central foveal thickness $(p=0.017)$ and fewer hyperreflective dots $(p=$ $0.028)$ compared with nonvitrectomized. Thirty (73\%) patients presented a significant functional improvement with
\end{abstract}

karger@karger.com www.karger.com/ore

Karger"

BOPEN ACCESS
(C) 2021 The Author(s)

Published by S. Karger AG, Basel

This is an Open Access article licensed under the Creative Commons Attribution-NonCommercial-4.0 International License (CC BY-NC) (http://www.karger.com/Services/OpenAccessLicense), applicable to the online version of the article only. Usage and distribution for commercial purposes requires written permission.
$17(42 \%)$ increasing at least 15 ETDRS letters. Overall, 22 (54\%) eyes had a complete resolution of DME at the 12-month visit. Patients who needed additional therapy had a higher prevalence of subretinal fluid ( $42 \mathrm{vs.} 3 \%, p=0.005$ ) at baseline. Conclusions: This study supports the effectiveness of the FAc implant and reports significant changes at 12 months after FAc injection.

(c) 2021 The Author(s)

Published by S. Karger AG, Basel

\section{Introduction}

Diabetes was estimated to affect a total of 463 million people in 2019 [1]. It is expected that more than half a billion people will be living with diabetes in 2030 and will grow to around 700 million (10.9\%) by 2045 [1].

Macular edema is the main cause of vision loss in diabetic retinopathy [2]. A course of at least 3 intravitreal injections of antivascular endothelial growth factor (VEGF) is recommended as the first-line therapy for diabetic mac-

Bernardete Pessoa and André Ferreira are co-first authors and contributed equally to this work.

Correspondence to:

André Ferreira, andre.ferreira@ live.com.pt 
ular edema (DME) [3]. Insufficient response to antiVEGF deems the resource to corticosteroid intravitreal injections, although in some cases they can be the first option if patients are unsuitable for anti-VEGF therapy [3].

The 0.19-mg fluocinolone acetonide (FAc) implant (ILUVIEN ${ }^{\circledR}$; Alimera Sciences Ltd., Hampshire, UK) was approved for the treatment of vision impairment associated with chronic DME considered insufficiently responsive to available therapies such as anti-VEGF and shortterm corticosteroid intravitreal injections. Its approval was based on data from FAME studies [4] that presented visual benefits over a 3-year period of follow-up in nonvitrectomized patients. Real-world studies have shown that the FAc implant is effective in both nonvitrectomized and vitrectomized eyes [5-10].

The main goal of this study was to quantitatively assess functional and structural features in nonvitrectomized and vitrectomized DME patients after being treated with an FAc implant. That purpose was enhanced by a comprehensive analysis of quantitative structural optical coherence tomography (OCT) biomarkers which have been correlated with severity and chronicity of DME, retina function, and influence in DME treatment response, which particularly deepen the knowledge of their potential role in predictive response to FAc therapy [11-17].

\section{Methods}

A retrospective review was conducted involving consecutive patients with DME who received a single intravitreal injection of the FAc implant at the Centro Hospitalar Universitário do Porto (CHUP), Portugal. The study was designed to analyze the presence of quantitative structural OCT biomarkers at baseline and 12 months after FAc therapy according to vitreous status: vitrectomized eyes (group 1) and nonvitrectomized eyes (group 2). The secondary objectives were to analyze differences in treatment response and the need for additional therapy as well as to correlate those biomarkers with response to therapy. The study was conducted according to the tenets of the Declaration of Helsinki in its latest amendment (Brazil, 2013) and was approved by the Ethics Committee of CHUP (2017.093 [084-DEFI/082-CES]). All patients signed an informed consent form.

\section{Study Population and Data}

Inclusion Criteria

Inclusion criteria were (1) type 1 or type 2 diabetes mellitus; (2) older than 18 years; (3) center-involved DME (central subfield foveal thickness [CFT] of $>300 \mu \mathrm{m}$ in the presence of intraretinal fluid), refractory to anti-VEGF and short-term steroid agents; (4) first treatment with FAc implant; and (5) both eyes (if indicated) could be included in this study. Refractory DME was defined as persistent intraretinal and/or subretinal fluid (SRF) on Spectral Domain-Optical Coherence Tomography (SD-OCT), after at least 3
anti-VEGF injections that were given at monthly intervals or 6 months after 1 short-term steroid injection, regardless of visual acuity.

\section{Exclusion Criteria}

Exclusion criteria were (1) other concomitant ocular diseases that cause macular edema or compromise visual acuity (as significant vitreoretinal interface abnormality on SD-OCT that might contribute to macular edema, such as ERM with inner retinal distortion, age-related macular degeneration, retinal vascular occlusion, central corneal opacity, amblyopia, advanced glaucoma, and optic neuropathy), except for the presence of cataract; (2) history of ocular trauma; (3) any intraocular surgery except uncomplicated cataract extraction and/or vitrectomy (in group 1 ) in $<3$ and 6 months before FAc, respectively; (4) previous treatment with intraocular corticosteroids within the 6 months before treatment with the FAc implant; and (5) inability or unwillingness to provide informed consent.

\section{Procedures}

Patient charts were reviewed for demographic data and previous treatments for DME. Based on the knowledge that steady-state aqueous FAc levels are achieved around 6 months after implantation and then maintained throughout to month 36 [18], we chose to assess patients 12 months after the injection of the FAc implant. At baseline and 12 months after FAc implant visits, assessment of BCVA using Early Treatment of Diabetic Retinopathy Study (ETDRS) letters chart, applanation tonometry, slit-lamp examination, dilated fundus examination, and SD-OCT (Heidelberg Spectralis, Heidelberg, Germany) was performed.

\section{SD-OCT Parameters}

CFT was calculated automatically by using the instrument. The presence of 9 different morphological parameters was determined using SD-OCT and measured with the $1-\mathrm{mm}$ central foveal area. These included (1) the presence of SRF; (2) the number of hyperreflective dots (HRD); (3) the disorganization of retinal inner layers; (4) the disruption of outer plexiform layer (OPL); (5) the disruption of external limiting membrane (ELM); (6) the disruption of ellipsoid zone (EZ); (7) the presence of cysts in the outer nuclear layer $(\mathrm{ONL}) ;(8)$ the presence of cysts in the inner nuclear layer (INL); and (9) the number of cysts in ONL versus those in the INL.

Disruption of OPL, ELM, and EZ was defined as an evident discontinuity in those layers. HRD were defined as small ( $<30 \mathrm{mi}-$ crons) and punctiform, with reflectivity similar to the nerve fiber layer and no backshadowing. The presence of the 9 SD-OCT parameters was assessed in the central $1 \mathrm{~mm}$ of 5 scans: the foveal one and the 2 above and the 2 below it.

OCT scans were obtained by using an SD-OCT (macular dense line scan mode HR $20 \times 20^{\circ}$ Spectralis HRA + OCT; Heidelberg Engineering, Heidelberg, Germany). All measurements were determined by 2 highly trained medical doctors (A.F. and J.L.) with disagreements solved by a third senior medical retinal specialist (B.P.).

\section{Functional and Anatomical Outcomes Criteria}

A significant functional improvement was considered a gain of at least 5 ETDRS letters [19]. DME resolution was defined by CFT $\leq 300 \mu \mathrm{m}$. The type of response was classified as (1) a good responder when at 12 months after FAc implant, there was DME resolution with a significant functional improvement without ad- 
Table 1. Baseline clinical and demographic characteristics of population

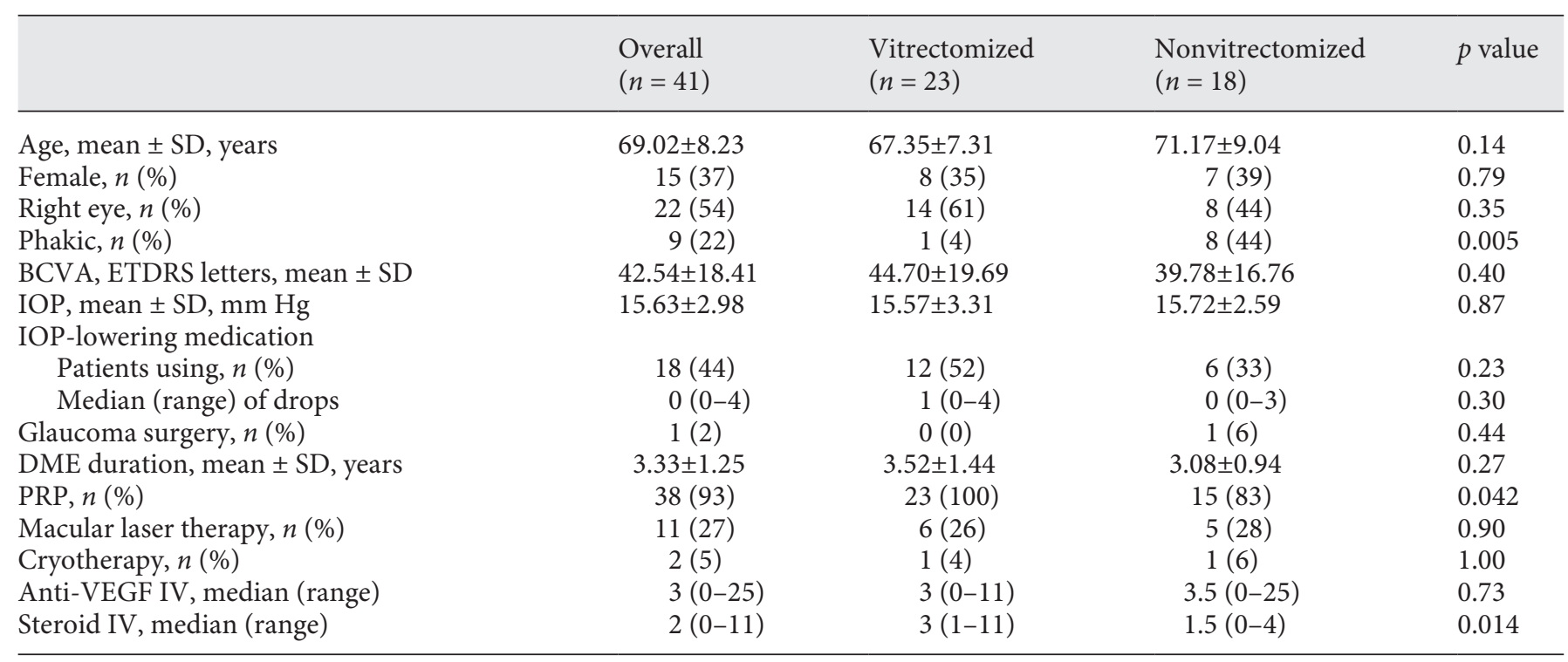

BCVA, best-corrected visual acuity; DME, diabetic macular edema; IOP, intraocular pressure; IV, intravitreal; PRP, panretinal photocoagulation; VEGF, vascular endothelial growth factor.

ditional treatments; (2) nonresponder, when there was a CFT $>400$ $\mu \mathrm{m}$ or $\leq 10 \%$ of CFT reduction and BCVA decrease (or BCVA gain $<5$ letters); (3) moderate responder - between good and nonresponder criteria; and (4) nongood responders include nonresponders and moderate responders. Macular atrophy was considered as CFT $<230 \mu \mathrm{m}[20]$.

\section{Statistical Analysis}

All statistical analyses were performed using Stata software (StataCorp. 2015. Stata Statistical Software: Release 14. College Station, TX, USA: StataCorp LP). Shapiro-Wilk, KolmogorovSmirnov test, and normal probability plots were used to confirm the normal distribution of the data. Parametric or nonparametric tests were used for continuous variable comparison between defined groups, according to the normality of data. $\chi^{2}$ or Fisher's exact tests were performed for categorical variable comparison. Statistical significance was defined as $p$ value $<0.05$.

\section{Results}

A total of 41 eyes from 30 patients were included in this study. Table 1 summarizes baseline clinical and demographic characteristics for the full population with statistical comparison between groups. Table 2 summarizes clinical and SD-OCT biomarkers before and after FAc implant. At 12 months after injection, BCVA was significantly higher compared with baseline $(p=0.005)$ with a mean increase of $12.3 \pm 18.6$ ETDRS letters. CFT was sig- nificantly lower at 12 months $(p<0.001)$ with a mean reduction of $198.2 \pm 211.3 \mu \mathrm{m}$. The prevalence of SRF ( $p=$ $0.026)$ and the number of $\operatorname{HRD}(p<0.001)$ and cysts in INL $(p<0.001)$ and ONL $(p<0.001)$ were significantly lower after the FAc implant. Despite nonsignificant, there was a trend for other anatomical improvements, namely, a lower prevalence of OPL, ELM, and EZ disruption.

No cases underwent cataract surgery or vitrectomy in the first 12 months of follow-up. Macular atrophy was observed in 5 cases, 3 (13\%) in group 1 and $2(11 \%)$ in group 2.

\section{Between-Group Demographic and Response to FAc} Implant Differences

In group 1 , more patients were pseudophakic ( $p=$ $0.005)$, more patients had been submitted to PRP ( $p=$ 0.042 ), and the number of previous steroid intravitreal injections was higher $(p=0.014)$ (Table 1). No other significant differences were found $(p>0.05)$ at baseline. At 12 months after the implant, lower IOP $(p=0.033)$, lower CFT $(p=0.017)$, and fewer HRD $(p=0.028)$ were observed in group 1 compared with group 2 . There was a trend towards a lower need of additional treatment in group 1 (OR 0.26; 95\%: 0.06-1.09, $p=0.066$ ). No differences were found regarding the response to treatment (35 vs. $28 \%$ of good responders, $p=0.74$, in groups 1 and 2 , respectively). 
Table 2. Clinical variables and SD-OCT biomarkers before and 12 months after FAc implant

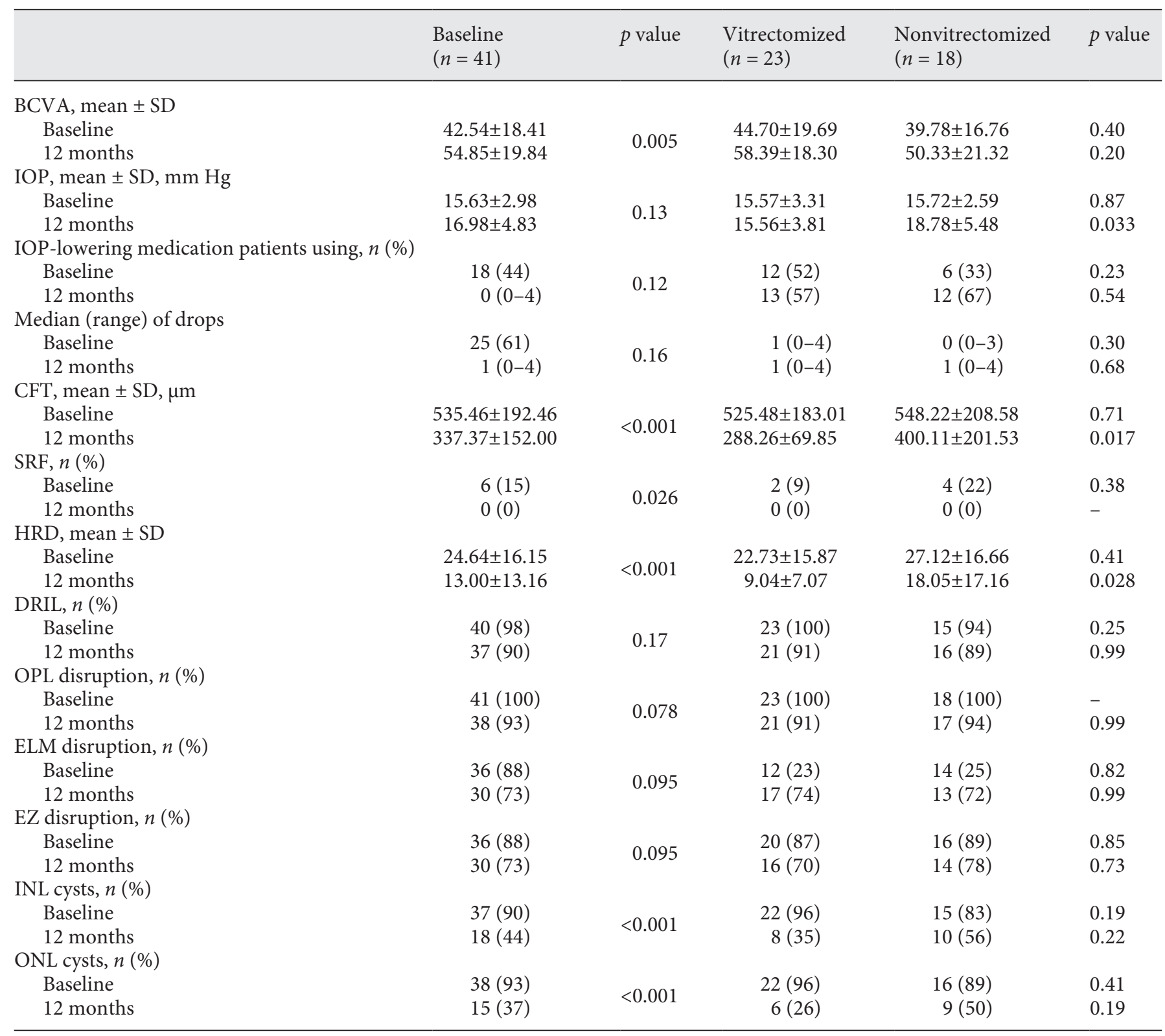

FAc, fluocinolone acetonide; BCVA, best-corrected visual acuity; CFT, central foveal thickness; SRL, subretinal fluid; DRIL, disorganization of retinal inner layers; ELM, external limiting membrane; EZ, ellipsoid zone; HRD, hyperreflective dots; INL, inner nuclear layer; IOP, intraocular pressure; ONL, outer nuclear layer; OPL, outer plexiform layer.

\section{Response to FAc Implant}

At 12 months after FAc implant, 30 (73\%) patients presented a significant functional improvement with 17 (42\%) having an increase of at least 15 ETDRS letters. Moreover, 22 (54\%) patients had a DME resolution while $9(22 \%)$ had a CFT $>400 \mu \mathrm{m}$. Lower baseline BCVA was associated with an increase of at least 15 ETDRS letters
$(34.1 \pm 11.6$ vs. $48.5 \pm 20.1, p=0.012)$ after injection of the FAc implant. Baseline SRF was also associated with an increase of at least 15 ETDRS letters in BCVA (29 vs. $4 \%$, $p=0.036)$ and with CFT above $400 \mu \mathrm{m}$ (44 vs. $6 \%, p=$ $0.004)$ at 12 months after implant.

Overall, 13 (32\%) eyes were judged to be good responders and $3(7 \%)$ bad responders; therefore, $61 \%$ of 
Fig. 1. SD-OCT of good and nongood responders at baseline (before treatment) and 12 months after FAc implant (after treatment). FAc, fluocinolone acetonide.

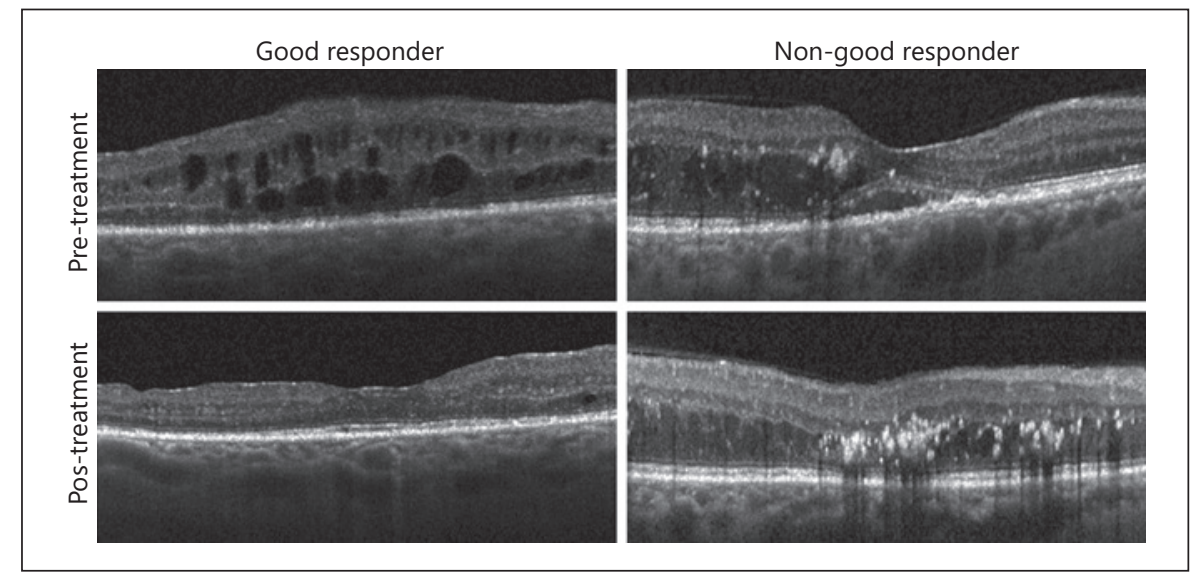

eyes had a moderate response. Figure 1 illustrates the SDOCT scans of representative cases of good and nongood responders at baseline and 12 months after FAc implant. Regarding the 5 cases without functional improvement despite a DME resolution (which explains different percentages of functional improvement vs. DME resolution, 41 and 54\%, respectively), they were all pseudophakic, with a better BCVA before FAc (mean + SD of $57.20 \pm$ 16.24 vs. $34.23 \pm 13.80$ ETDRS letters, $p=0.005)$, and there was a trend for them to be younger (mean $\pm \mathrm{SD}$ $63.40 \pm 6.84$ vs. $70.82 \pm 8.29$ years, $p=0.08)$, to have a higher DME duration (mean \pm SD $4.6 \pm 1.85 \pm 3.35 \pm 1.21$ years, $p=0.087$ ), and to have been submitted to a higher number of anti-VEGF intravitreal injections before FAc (median [range] $5[1-8]$ vs. 1 [0-9], $p=0.06$ ) compared with good responders.

Table 3 summarizes baseline characteristics and SDOCT parameters by response to treatment. At baseline, when compared with the nongood responders, the eyes with good response had a tendency towards lower BCVA $(p=0.052)$ and lower prevalence of SRF $(p=0.084)$ and had received fewer prior injections of anti-VEGF ( $p=$ 0.008 ; Table 3). At 12 months after the implant, in comparison with nongood responders, the eyes with good response had lower CFT $(p=0.012)$ and fewer HRD $(p=$ 0.042).

\section{Need for Additional Therapy}

Overall, 12 (29\%) eyes needed additional therapy in the first 12 months after implant and all were submitted to further anti-VEGF injections. At baseline, patients that required supplemental therapy had a higher CFT (646.25 \pm 185.45 vs. $489.62 \pm 178.79 \mu \mathrm{m}, p=0.016)$ and a higher prevalence of SRF (42 vs. $3 \%, p=0.005$ ). At 12 months, those patients presented a higher number of HRD (20.00 \pm 18.98 vs. $10.10 \pm 8.73, p=0.026)$. Further comparisons at baseline and at 12 months concerning demographic, clinical, and SD-OCT parameters were made, and no other significant differences were observed.

\section{Discussion}

This study supports the effectiveness of the FAc implant in the treatment of persistent or recurrent DME and reports significant changes in several SD-OCT parameters (CFT, SRF, HRD, INL, and ONL cysts) and BCVA 12 months after FAc injection. Comparisons between groups revealed that after 12 months, vitrectomized eyes had lower IOP, lower CFT, fewer HRD, and a trend towards a lower need for additional treatment. However, there was no difference in the response to the FAc implant between groups according to the criteria hereby defined. Data also suggest that biomarkers at baseline (i.e., higher CFT and higher prevalence of SRF) and at 12 months (i.e., higher number of HRD) may be important indicators as to whether additional therapy will be needed. This study emphasizes the important role of FAc in the treatment of DME that persists or recurs despite treatment and its positive effect on visual outcomes as well as SD-OCT parameters and are generally consistent with the published literature.

The main goal of this study was to quantitatively assess functional and structural features in nonvitrectomized and vitrectomized DME patients after being treated with an FAc implant, which is important as a history of vitrectomy was an exclusion criterion in the FAME/FAMOUS studies $[4,18,21]$, and to the best of our knowledge, this is the first study to assess the importance of SD-OCT biomarkers in these eyes following therapy with the FAc im- 
Table 3. Clinical and SD-OCT parameters according to type of response

\begin{tabular}{|c|c|c|c|}
\hline & $\begin{array}{l}\text { Good response } \\
(n=14)\end{array}$ & $\begin{array}{l}\text { Nongood response } \\
(n=28)\end{array}$ & $p$ value \\
\hline Age, mean $\pm S D$, years & $71.85 \pm 7.87$ & $67.71 \pm 8.20$ & 0.14 \\
\hline Female, $n(\%)$ & $4(31)$ & $11(39)$ & 0.73 \\
\hline Right eye, $n(\%)$ & $9(69)$ & $13(46)$ & 0.17 \\
\hline Phakic, $n(\%)$ & $2(15)$ & $7(25)$ & 0.69 \\
\hline Glaucoma surgery, $n(\%)$ & $0(0)$ & $1(4)$ & 0.99 \\
\hline Previous vitrectomy, $n(\%)$ & $8(62)$ & $15(54)$ & 0.71 \\
\hline DME duration, mean \pm SD, years & $3.42 \pm 1.22$ & $3.28 \pm 1.29$ & 0.75 \\
\hline $\mathrm{PRP}, n(\%)$ & $12(92)$ & $26(93)$ & 0.99 \\
\hline Macular laser, $n(\%)$ & $3(23)$ & $8(29)$ & 0.99 \\
\hline Cryotherapy, $n(\%)$ & $1(8)$ & $1(4)$ & 0.54 \\
\hline Anti-VEGF IV, median (range) & $1(0-9)$ & $4.5(0-25)$ & 0.008 \\
\hline Steroid IV, median (range) & $3(1-7)$ & $2(0-11)$ & 0.57 \\
\hline \multicolumn{4}{|l|}{$\mathrm{BCVA}$, mean $\pm \mathrm{SD}$} \\
\hline Baseline & $34.38 \pm 13.47$ & $46.32 \pm 19.35$ & 0.052 \\
\hline 12 months & $55.92 \pm 15.81$ & $54.35 \pm 21.71$ & 0.82 \\
\hline \multicolumn{4}{|l|}{$\mathrm{IOP}$, mean $\pm \mathrm{SD}, \mathrm{mm} \mathrm{Hg}$} \\
\hline Baseline & $14.77 \pm 2.55$ & $16.03 \pm 3.12$ & 0.21 \\
\hline 12 months & $17.77 \pm 4.13$ & $16.61 \pm 5.16$ & 0.48 \\
\hline \multicolumn{4}{|c|}{ IOP-lowering medication patients using, $n(\%)$} \\
\hline Baseline & $7(54)$ & $11(39)$ & 0.50 \\
\hline 12 months & $8(62)$ & $17(61)$ & 0.99 \\
\hline \multicolumn{4}{|l|}{ Median (range) of drops } \\
\hline Baseline & $1(0-4)$ & $0(0-3)$ & 0.32 \\
\hline 12 months & $1(0-4)$ & $1(0-4)$ & 0.80 \\
\hline \multicolumn{4}{|l|}{$\mathrm{CFT}$, mean $\pm \mathrm{SD}, \mu \mathrm{m}$} \\
\hline Baseline & $526.46 \pm 222.73$ & $539.64 \pm 181.02$ & 0.84 \\
\hline 12 months & $251.54 \pm 23.14$ & $377.21 \pm 169.69$ & 0.012 \\
\hline \multicolumn{4}{|l|}{ SRF, $n(\%)$} \\
\hline Baseline & $0(0)$ & $6(21)$ & 0.084 \\
\hline 12 months & $0(0)$ & $0(0)$ & - \\
\hline \multicolumn{4}{|l|}{$\mathrm{HRD}$, mean $\pm \mathrm{SD}$} \\
\hline Baseline & $24.33 \pm 22.32$ & $24.78 \pm 13.06$ & 0.94 \\
\hline 12 months & $6.92 \pm 7.69$ & $15.82 \pm 14.29$ & 0.042 \\
\hline \multicolumn{4}{|l|}{ DRIL, $n(\%)$} \\
\hline Baseline & $13(100)$ & $27(96)$ & 0.99 \\
\hline 12 months & $11(85)$ & $26(93)$ & 0.58 \\
\hline \multicolumn{4}{|l|}{ OPL disruption, $n(\%)$} \\
\hline Baseline & $13(100)$ & $28(100)$ & - \\
\hline 12 months & $12(92)$ & $26(93)$ & 0.99 \\
\hline \multicolumn{4}{|l|}{ ELM disruption, $n(\%)$} \\
\hline Baseline & $13(100)$ & $23(82)$ & 0.16 \\
\hline 12 months & $12(92)$ & $18(64)$ & 0.061 \\
\hline \multicolumn{4}{|l|}{ EZ disruption, $n(\%)$} \\
\hline Baseline & $12(92)$ & $24(86)$ & 0.99 \\
\hline 12 months & $11(85)$ & $19(68)$ & 0.45 \\
\hline \multicolumn{4}{|l|}{ INL cysts, $n(\%)$} \\
\hline Baseline & $11(85)$ & $26(93)$ & 0.58 \\
\hline 12 months & $5(38)$ & $13(46)$ & 0.74 \\
\hline \multicolumn{4}{|l|}{ ONL cysts, $n(\%)$} \\
\hline Baseline & $12(92)$ & $26(93)$ & 0.99 \\
\hline 12 months & $4(31)$ & $11(39)$ & 0.73 \\
\hline
\end{tabular}


Table 3 (Footnote)

BCVA, best-corrected visual acuity; CFT, central foveal thickness; DME, diabetic macular edema; SRL, subretinal fluid; DRIL, disorganization of retinal inner layers; ELM, external limiting membrane; EZ, ellipsoid zone; HRD, hyperreflective dots; INL, inner nuclear layer; IOP, intraocular pressure; IV, intravitreal; ONL, outer nuclear layer; OPL, outer plexiform layer; PRP, panretinal photocoagulation; VEGF, vascular endothelial growth factor.

plant. Baseline characteristics revealed that the vitrectomized group had a higher prevalence of pseudophakia and PRP treatment as well as a higher number of steroid intravitreal injections at baseline, with no other significant differences with regard to vitreous status. This may be explained by a higher severity of DME in vitrectomized eyes, as DME duration was similar in both groups.

Despite the lower CFT, lower IOP, and number of HRD in the vitrectomized group at month 12, no differences were found in the response to the FAc implant between vitrectomized and nonvitrectomized patient eyes. Other reports $[6,8,10]$ have demonstrated the effectiveness of the FAc implant in vitrectomized and/or nonvitrectomized patient eyes. The current study, however, expands our understanding of SD-OCT biomarkers. This is important as they are considered relevant to functional outcomes and responses to DME therapy [11-17]. Here, we showed that vitrectomized eyes had fewer HRD compared with nonvitrectomized eyes at month 12 . This was also observed in the subgroup analysis where good responders had lower HRD than nongood responders. According to Framme et al. [12], the number of HRD correlates with the severity of DME. It is also suggested to be a predictive factor for therapeutic outcomes and a hallmark of inflammatory retina tissue response [14].

The role of pars plana vitrectomy (PPV) in tractional DME is undoubtedly helpful while in nontractional DME, it remains controversial. Some theories advocate that PPV would eliminate some inflammatory mediators that contribute to vessel permeability and that it would normalize macular blood supply with decreased leakage [22]. In addition to the reduced vitreous viscosity due to vitreous removal, which increases the diffusion of molecules through the eye, promoting higher premacular oxygen concentrations and lower intraretinal VEGF concentrations, endo-PRP, usually performed during vitrectomy, may enhance its positive effect in DME control [23]. However, PPV may also lead to quicker drug diffusion and clearance, reducing the exposure to the treatment [22]. Our achievements may support the anti-inflammatory role of PPV enforcing the view that this procedure may act as an additional treatment for DME irrespective of tractional status. In fact, vitrectomized patients presented a tendency towards a lower need for additional treatment.

The importance of these findings may be relevant in the remaining course of the disease, as a more benign DME evolution through disease stabilization and less additional treatments, particularly in vitrectomized eyes $[24,25]$. The lower CFT in vitrectomized eyes after 12 months of FAc treatment is also in line with the association of vitrectomy with macula atrophy, particularly when internal limiting membrane peeling is performed $[20,25,26]$. In this study, all vitrectomized eyes had undergone internal limiting membrane peeling [23]. Nonetheless, macular atrophy was observed in a low and similar number of cases in both groups. Regarding lower IOP in vitrectomized eyes at the end of follow-up seems not to be so clinically relevant as mean IOP and the median number of IOP-lowering medications were similar in both groups.

There was a difference in the number of prior steroid injections at baseline with the vitrectomized group having a higher number of treatments. However, this does not seem to explain the discrepancies at 12 months as both triamcinolone and dexamethasone implants have a short duration of action.

The current study also assessed SD-OCT parameters at baseline and, in-line with the literature, a higher CFT $[27,28]$, a higher number of $\mathrm{HRD}$, and the presence of SRF [29] were associated with a more chronic and severe DME and the need for additional treatment in the first 12 months after FAc implant. This last finding was already expected as SRF is a predictor for anatomical resolution with anti-VEGF and steroid therapy, and its presence is associated with additional therapy burden to achieve DME regression [15, 17, 19, 24-26, 28]. This last fact justifies the trend toward a lack of good response among patients with SRF at baseline as our criteria included the absence of additional treatment. The need for additional therapy in eyes with a higher number of HRD also supports the hypothesis that HRD reflects increased disease 
state and inflammatory activity [14]. Contrary to our study, Arrigo et al. [30] reported an association between higher CFT at baseline and good response to the FAc implant at month 12 . This may be explained by their criteria where a good responder was based on the CFT outcome (improvement of at least 30\%). Based on the published literature [27, 31], however, there is good argumentation that a higher mean CFT ( 535 vs. $476 \mu \mathrm{m}$ ) precludes a more chronic and refractory DME and the anticipation of a poor anatomical and functional outcome with a higher expectancy for additional therapies. The predictive value of prior PRP, as reported by Cicinelli et al. [29], could not be reproduced in our study and is probably explained by the low number of eyes without PRP $(n=3)$.

Limitations of the present study include its retrospective design and all its implications. The number of patients did not allow us to perform multivariable analysis; therefore, our conclusions might be misled by confounders. When 2 eyes of the same patient fulfilled the inclusion criteria, both were used but due to the small sample, no advanced statistical analyses were performed to adjust for the potential correlation between those eyes. Our population is a cohort of diabetic patients that are well known for their clinical heterogeneity. Further studies are needed to clarify all the implications of those baseline changes in the prognosis of these patients.

\section{Conclusion}

This study supports the effectiveness of the FAc implant in the treatment of persistent or recurrent DME and reports significant changes in several SD-OCT parameters at 12 months after FAc injection, besides the improvement of visual acuity, particularly in vitrectomized eyes, with lower CFT and number of HRD at 12 months after treatment and a trend to less additional therapy. SRF was the other important prognostic biomarker, with a clear connotation with the need of additional therapy. The importance of these findings may be relevant in the remaining course of the disease, as a more benign DME evolution through disease stabilization and less additional treatments, particularly in vitrectomized eyes. Moreover, the results hereby presented shed light on the relevance of biomarkers in treatment decisions and prognosis. Future studies with larger samples and longer follow-up should be carried out to further investigate and confirm our results.

\section{Statement of Ethics}

The study was conducted according to the tenets of the Declaration of Helsinki in its latest amendment (Brazil, 2013) and was approved by the Ethics Committee of CHUP (2017.093 [084-DEFI/082-CES]). All patients signed an informed consent form.

\section{Conflict of Interest Statement}

The authors have no conflicts of interest to declare.

\section{Funding Sources}

The authors have no funding to declare.

\section{Author Contributions}

Study design: B.P., J.F., A.M., and J.M.B. Data acquisition: B.P., A.F., and J.L. Data analysis: A.F. Critical interpretation of data: B.P. and A.F. Manuscript drafting: B.P. and A.F. Manuscript critical review: all. Final approval of the manuscript: all.

\section{References}

1 Saeedi P, Petersohn I, Salpea P, Malanda B, Karuranga S, Unwin N, et al. Global and regional diabetes prevalence estimates for 2019 and projections for 2030 and 2045: results from the international diabetes federation diabetes atlas, 9th edition. Diabetes Res Clin Pract. 2019 Nov; 157:107843.

2 Lee R, Wong TY, Sabanayagam C. Epidemiology of diabetic retinopathy, diabetic macular edema and related vision loss. Eye Vis. 2015; 2:17.

3 Estebainha R, Goldhardt R, Falcão M. A new approach for diabetic macular edema treatment: review of clinical practice results with
$0.19 \mathrm{mg}$ fluocinolone acetonide intravitreal implant including vitrectomized eyes. Curr Ophthalmol Rep. 2020 Mar;8(1):1-10.

4 Campochiaro PA, Brown DM, Pearson A, Chen S, Boyer D, Ruiz-Moreno J, et al. Sustained delivery fluocinolone acetonide vitreous inserts provide benefit for at least 3 years in patients with diabetic macular edema. Ophthalmology. 2012 Oct;119(10):2125-32.

5 Alfaqawi F, Lip PL, Elsherbiny S, Chavan R, Mitra A, Mushtaq B. Report of 12-months efficacy and safety of intravitreal fluocinolone acetonide implant for the treatment of chronic diabetic macular oedema: a real-world re- sult in the United Kingdom. Eye. 2017 Apr; 31(4):650-6.

6 El-Ghrably I, Steel DHW, Habib M, Vaideanu-Collins D, Manvikar S, Hillier RJ. Diabetic macular edema outcomes in eyes treated with fluocinolone acetonide $0.2 \mu \mathrm{g} / \mathrm{d}$ intravitreal implant: real-world UK experience. Eur J Ophthalmol. 2017 May 11;27(3):357-62.

7 Holden SE, Currie CJ, Owens DR. Evaluation of the clinical effectiveness in routine practice of fluocinolone acetonide $190 \mu \mathrm{g}$ intravitreal implant in people with diabetic macular edema. Curr Med Res Opin. 2017 Oct;33(Suppl 2):5-17. 
8 Meireles A, Goldsmith C, El-Ghrably I, Erginay A, Habib M, Pessoa B, et al. Efficacy of $0.2 \mu \mathrm{g} /$ day fluocinolone acetonide implant (ILUVIEN) in eyes with diabetic macular edema and prior vitrectomy. Eye. 2017 May; 31(5):684-90.

9 Fusi-Rubiano W, Mukherjee C, Lane M, Tsaloumas MD, Glover N, Kidess A, et al. Treating diabetic macular oedema (DMO): real world UK clinical outcomes for the 0.19 $\mathrm{mg}$ fluocinolone acetonide intravitreal implant (Iluvien) at 2 years. BMC Ophthalmol. 2018 Feb 27;18(1):62.

10 Pessoa B, Coelho J, Correia N, Ferreira N, Beirao M, Meireles A. Fluocinolone acetonide intravitreal implant $190 \mu \mathrm{g}\left(\right.$ ILUVIEN $\left.^{\circledR}\right)$ in vitrectomized versus nonvitrectomized eyes for the treatment of chronic diabetic macular edema. Ophthalmic Res. 2018;59(2):68-75.

11 Maheshwary AS, Oster SF, Yuson RM, Cheng L, Mojana F, Freeman WR. The association between percent disruption of the photoreceptor inner segment-outer segment junction and visual acuity in diabetic macular edema. Am J Ophthalmol. 2010 Jul;150(1):63-e1.

12 Framme C, Schweizer P, Imesch M, Wolf S, Wolf-Schnurrbusch U. Behavior of SD-OCTdetected hyperreflective foci in the retina of anti-VEGF-treated patients with diabetic macular edema. Invest Ophthalmol Vis Sci. 2012 Aug 24;53(9):5814-8.

13 Reznicek L, Cserhati S, Seidensticker F, Liegl R, Kampik A, Ulbig M, et al. Functional and morphological changes in diabetic macular edema over the course of anti-vascular endothelial growth factor treatment. Acta Ophthalmol. 2013 Nov;91(7):e529-36.

14 Vujosevic S, Bini S, Midena G, Berton M, Pilotto E, Midena E. Hyperreflective intraretinal spots in diabetics without and with nonproliferative diabetic retinopathy: an in vivo study using spectral domain OCT. J Diabetes Res. 2013;2013:491835.

15 Sun JK, Radwan SH, Soliman AZ, Lammer J, Lin MM, Prager SG, et al. Neural retinal disorganization as a robust marker of visual acuity in current and resolved diabetic macular edema. Diabetes. 2015 Jul;64(7):2560-70.
16 Ashraf M, Souka A, Adelman R. Predicting outcomes to anti-vascular endothelial growth factor (VEGF) therapy in diabetic macular oedema: a review of the literature. Br J Ophthalmol. 2016 Dec;100(12):1596-604.

17 Vujosevic S, Torresin T, Berton M, Bini S, Convento E, Midena E. Diabetic macular edema with and without subfoveal neuroretinal detachment: two different morphologic and functional entities. Am J Ophthalmol. 2017 Sep;181:149-55.

18 Campochiaro PA, Nguyen QD, Hafiz G, Bloom S, Brown DM, Busquets M, et al. Aqueous levels of fluocinolone acetonide after administration of fluocinolone acetonide inserts or fluocinolone acetonide implants. Ophthalmology. 2013 Mar;120(3):583-7.

19 Gonzalez VH, Campbell J, Holekamp NM, Kiss S, Loewenstein A, Augustin AJ, et al. Early and long-term responses to anti-vascular endothelial growth factor therapy in diabetic macular edema: analysis of protocol I data. Am J Ophthalmol. 2016 Dec;172:72-9.

20 Iglicki M, Lavaque A, Ozimek M, Negri HP, Okada M, Chhablani J, et al. Biomarkers and predictors for functional and anatomic outcomes for small gauge pars plana vitrectomy and peeling of the internal limiting membrane in naive diabetic macular edema: the VITAL Study. PLoS One. 2018;13(7): e0200365.

21 Campochiaro PA, Hafiz G, Shah SM, Bloom S, Brown DM, Busquets M, et al. Sustained ocular delivery of fluocinolone acetonide by an intravitreal insert. Ophthalmology. 2010 Jul;117(7):1393-e3.

22 Chen YY, Chen PY, Chen FT, Chen YJ, Wang JK. Comparison of efficacy of intravitreal ranibizumab between non-vitrectomized and vitrectomized eyes with diabetic macular edema. Int Ophthalmol. 2018 Feb;38(1):293-9.

23 Stefansson E. The therapeutic effects of retinal laser treatment and vitrectomy. A theory based on oxygen and vascular physiology. Acta Ophthalmol Scand. 2001 Oct;79(5):43540.
24 Iuliano L, Corbelli E, Bandello F, Codenotti M. Protective effect of vitrectomy on the course of diabetic retinopathy: a case report. Eur J Ophthalmol. 2020 Nov 4; 1120672120968739.

25 Pessoa B, Melo-Beirao J, Meireles A, Meneres P. Challenging clinical cases: a walk through supplemental therapy with intravitreal ranibizumab therapy following treatment of diabetic macular edema with the $0.19 \mathrm{mg}$ fluocinolone acetonide implant (ILUVIEN ${ }^{\circledR}$ ). Int Med Case Rep J. 2020;13:437-48.

26 Yanyali A, Nohutcu AF, Horozoglu F, Celik E. Modified grid laser photocoagulation versus pars plana vitrectomy with internal limiting membrane removal in diabetic macular edema. Am J Ophthalmol. 2005 May;139(5): 795-801.

27 Sivaprasad S, Crosby-Nwaobi R, Heng LZ, Peto T, Michaelides M, Hykin P. Injection frequency and response to bevacizumab monotherapy for diabetic macular oedema (BOLT Report 5). Br J Ophthalmol. 2013 Sep;97(9): 1177-80.

28 Yoshitake T, Murakami T, Suzuma K, Fujimoto M, Dodo Y, Tsujikawa A. Predictor of early remission of diabetic macular edema under as-needed intravitreal ranibizumab. Sci Rep. 2019 May 20;9(1):7599.

29 Cicinelli MV, Rabiolo A, Zollet P, Capone L, Lattanzio R, Bandello F. Persistent or recurrent diabetic macular edema after fluocinolone acetonide $0.19 \mathrm{mg}$ implant: risk factors and management. Am J Ophthalmol. 2020 Jul;215:14-24.

30 Arrigo A, Capone L, Lattanzio R, Aragona E Zollet P, Bandello F. Optical coherence tomography biomarkers of inflammation in diabetic macular edema treated by fluocinolone acetonide intravitreal drug-delivery system implant. Ophthalmol Ther. 2020 Sep 10;9(4): 971-80.

31 Bailey C, Chakravarthy U, Lotery A, Menon G, Talks J, Medisoft Audit G. Real-world experience with $0.2 \mu \mathrm{g} /$ day fluocinolone acetonide intravitreal implant (ILUVIEN) in the United Kingdom. Eye. 2017 Dec;31(12): 1707-15.
Tomographic Biomarkers in Diabetic Macular Edema
Ophthalmic Res 2021;64:639-647

DOI: $10.1159 / 000515306$ 